\title{
MICROPROPAGAÇÃO DE HIPPEASTRUM HYBRIDUM 'APPLE BLOSSOM', MEDIANTE ESCAMAS DUPLAS'
}

\author{
ANTONIO FERNANDO CAETANO TOMBOLATO ${ }^{2,3}$; ANA MARIA MOLINI COSTA ${ }^{2,3}$ \\ e ALESSANDRA C. EGLIT ${ }^{2,3}$
}

\begin{abstract}
RESUMO
Uma série de experimentos foi realizada para a definição de um protocolo visando à produção massal in vitro de Hippeastrum hybridum Hort., var. 'Apple Blossom' por explante de bulbo. No primeiro experimento, testaram-se combinações de ácido 3indolacético (AIA), nas concentrações de 0,$0 ; 2,5$ e 5,0 mg. $\mathrm{L}^{-1}$ e 6-benzilaminopurina (6-BA), nas concentrações de 0,$0 ; 5,0 ; 10,0$ e 20,0 mg. $\mathrm{L}^{-1}$. No segundo, testaram-se diferentes doses das auxinas ácido 3-indolacético (AIA), ácido alfa-naftalenoacético (ANA) e ácido 3-indolbutírico (AIB), nas concentrações de 2,5 e 5,0 mg.L $\mathrm{L}^{-1}$, em combinação com 10,0 mg. $\mathrm{L}^{-1}$ da citocinina 6-BA. No primeiro experimento, concluiu-se que, para qualquer das concentrações testadas, a presença da auxina AIA não exerceu influência sobre o número de bulbilhos formados. No segundo experimento observou-se que a alteração do tipo da auxina interferiu na quantidade de raízes formadas. Os meios mais favoráveis para a multiplicação são aqueles que induzem baixa formação de raízes e elevada bulbificação. Dessa forma, a constituição de reguladores de crescimento mais indicada é AIA a 2,5 mg.L-1 e 6-BA a 10 mg.L-1
\end{abstract}

Palavras-chave: amarílis, Amaryllis, micropropagação, cultura de tecido.

\section{ABSTRACT \\ Micropropagation of Hippeastrum hybridum 'Apple Blossom', by twin scale}

Some experiments were carried out to establish a protocol aiming to micropropagate
Hippeastrum hybridum Hort. by bulb explant. In the first experiment different combinations of hormones were tested: 3 -indolacetic acid (IAA), at $0.0 ; 2.5$ and $5.0 \mathrm{mg} . \mathrm{L}^{-1}$ and 6-benzilaminopurine (6-BA), at 0.0 ; 5.0; 10.0 and $20.0 \mathrm{mg} . \mathrm{L}^{-1}$. On the second experiment, the auxins - 3-indolacético acid (IAA), alfanaftalenoacetic acid (NAA) and 3-indolbutiric acid (IBA) - were tested at the concentrations 2.5 and 5.0 mg. $\mathrm{L}^{-1}$ combined with $10.0 \mathrm{mg} . \mathrm{L}^{-1}$ of the citocinin 6BA. According to the statistics analysis of the results, in the first experiment was attested that only the 6-BA influenced the number of the bulblets produced. On the second experiment, it was observed that the type of auxin interfered on the quantity of generated roots. The NAA induced the formation of the largest number of roots. For the Hippeastrum mass propagation, it is important that the medium improve the number of bulblets with low quantity of roots. In this manner, the best medium obtained in these experiments contained $2.5 \mathrm{mg} . \mathrm{L}^{-1}$ of IAA and $10 \mathrm{mg} \cdot \mathrm{L}^{-1}$ of $6-\mathrm{BA}$.

Key words: Amaryllis, micropropagation, tissue culture.

\section{INTRODUÇÃO}

O cultivo de amarílis (Hippeastrum hybridum Hort.) alcançou, nas últimas décadas, grande importância econômica mundial. No Brasil, a preocupação com o melhoramento de seu processo de cultivo, inclusive na eliminação de microrganismos patogênicos, vem estimulando o desenvolvimento de um programa de melhoramento genético no Instituto Agronômico de Campinas (CASTRO \& MATTHES, 1987).

\footnotetext{
${ }^{1}$ Projeto desenvolvido com apoio parcial de CNPq e FAPESP.

${ }^{2}$ Instituto Agronômico - IAC - Centro de Horticultura, Caixa Postal 28, 13001-970 Campinas (SP).

${ }^{3}$ Bolsista CNPq.
} 
O amarílis tem sido intensamente comercializado no mercado mundial na forma de plantas envasadas, para uso em interiores e como bulbos induzidos ao florescimento, para plantio em jardins, formando maciços florais ou bordaduras e até como flor de corte.

Sua adaptação é excepcional, visto que grande número de espécies é nativo em nosso próprio País e em todo o continente sul-americano. A coloração das flores é variadíssima, apresentando todos os matizes de vermelho, vinho, salmão, branco, cobre, bronze e outras, conforme a espécie (TOMBOLATO \& MATTHES, 1998).

Nos países tradicionalmente produtores de amarílis, os híbridos são, normalmente, propagados mediante escamação dos bulbos (escamas duplas), separando-se secções de escamas juntamente com uma porção da placa basal, que produzem bulbilhos quando colocadas em substrato próprio (VIJVERBERG, 1981). Esse processo permite a obtenção de 60 a 70 bulbilhos a partir de um único bulbo de planta adulta. Embora essa técnica seja viável, há o problema do ataque de fungos que ocasionam a podridão das escamas, incentivadas pelas altas temperaturas predominantes em nosso clima. O desenvolvimento vegetativo é lento, necessitando de dois a três anos de cultivo para o florescimento.

A técnica de micropropagação in vitro possibilita a intensificação dessa multiplicação, viabilizando, igualmente, a probabilidade de encurtamento do ciclo vegetativo em vista da ação dos fitorreguladores empregados nos meios de cultura.

Outro entrave à expansão da cultura é o aparecimento de viroses do tipo mosaico, causada por vírus do tipo $\mathrm{Y}$, que afeta sensivelmente o desenvolvimento das plantas, comprometendo a qualidade dos bulbos produzidos e, conseqüentemente, das inflorescências.

Em virtude de tais dificuldades, o uso de técnicas de cultura in vitro adquire um papel extremamente importante, por permitir que problemas fundamentais, associados à multiplicação, melhoramento e sanidade, sejam solucionados. Portanto, a micropropagação de Hippeastrum visa, também, à limpeza de microrganismos endógenos, principalmente os vírus, favorecendo a obtenção de material básico sadio.
A aplicação das técnicas de cultura de tecidos em amarílis, possivelmente, iniciou-se com BELL (1972), que utilizou com êxito a solução de Hoagland modificada, por meio da inclusão de FeEDTA e maiores níveis de cálcio, para o cultivo de embriões imaturos de híbridos obtidos pelo cruzamento de plantas do clone 'Superba' com Hippeastrum evansiae.

Um método para a propagação in vitro de Hippeastrum sp. foi estabelecido por MII et al. (1974), que obtiveram o desenvolvimento de brotação de raízes a partir de tecidos retirados de escamas de bulbos e cultivados em meio MS (MURASHIGE \& SKOOG, 1962), suplementado com várias combinações de ANA e cinetina (KIN). A organogênese foi diretamente relacionada à presença da auxina, enquanto a presença de KIN, em concentrações elevadas, foi tóxica. Também HUSSEY (1975) verificou a necessidade de suplementação de auxinas ao meio básico de MS para ocorrência de organogênese em Hippeastrum hybridum.

A partir de explantes constituídos por tecidos de escamas de bulbos ou de anteras de híbridos de Hippeastrum, BAPAT \& NARAYANASWAMY (1976) estabeleceram sucessivos cultivos de calos. A indução de calos foi dependente da presença de água de coco e ácido 2,4-diclorofenoxiacético (2,4D), adicionados ao meio nutritivo de MS. A diferenciação das raízes e parte aérea levou ao desenvolvimento de plantas completas e somente ocorreu após a transferência dos tecidos para meio sem suplementação de auxina. BOSE \& JANA (1977), utilizando o meio modificado de Knudson C, suplementado com ANA, também obtiveram a regeneração de plântulas de híbridos de Hippeastrum.

Experimentos de YANAGAWA \& SAKANISHI (1977) demonstraram que a temperatura a $25-30^{\circ} \mathrm{C}$ favoreceu a formação de bulbilhos em tecidos de bulbos de Hippeastrum, cultivados em meio de WHITE (1951), suplementado com sacarose a $2 \%$ e ágar a $0,8 \%$. Embora a luz não tenha sido exigida para a indução à formação de bulbilhos, sua presença favoreceu o crescimento posterior. A utilização de explantes constituídos por segmentos contendo tanto tecido da porção basal das escamas, como da própria placa basal do bulbo, induziram a produção de bulbilhos na porção proximal das escamas e raízes nos tecidos da placa basal, embora o enraizamento só tenha ocorrido posteriormente. 
CASTRO \& MATTHES (1987), visando solucionar os problemas da propagação clonal de amarílis, desenvolveram um protocolo utilizando, como fonte de explantes, segmentos de escamas e da placa basal e raízes, inoculados em meio MS, suplementado com diferentes concentrações de ANA e 6-BA. Como explantes, as raízes foram descartadas, pois apresentaram alta incidência de contaminação e necrosaram com concentrações mais elevadas de solução desinfetante. Os explantes da placa basal com ou sem escamas de bulbos foram os mais adequados à micropropagação. O balanço hormonal foi determinante para a brotação, indução de calos ou formação de bulbilhos. As concentrações de 1,0 mM de ANA e 0,5-1,0 mg. $\mathrm{L}^{-1}$ de 6-BA favoreceram a indução de brotações, que iniciaram ao redor do $30 .^{\circ}$ dia e se aceleraram na presença de luz.

O'ROURKE et al. (1991) utilizaram explantes de pedicelo e do ovário de hastes florais, inoculados em meio MS contendo ANA e 6-BA, nas concentrações de 1,0 e $10,0 \mathrm{mg} / \mathrm{L}, 2,0$ e $5,0 \mathrm{mg} / \mathrm{L}$ e 2,0 e $10,0 \mathrm{mg} / \mathrm{L}$ respectivamente, emitindo plântulas depois de 32 semanas do início da cultura. Foram originadas 52 plântulas a partir de sete explantes.

DE BRUYN et al. (1992) desenvolveram uma técnica de propagação in vitro de Amaryllis belladona denominada de "escamas gêmeas" (do inglês "twin scale"), que se resume na obtenção do explante através do corte do bulbo, com a finalidade de formação de plântulas com a aplicação de ANA e 6-BA.

Embora procedimentos envolvendo o emprego de técnicas de cultivo in vitro tenham sido desenvolvidos, permanecem dúvidas quanto à adequação do meio nutricional, balanço hormonal, fonte de explantes e condições ambientes ideais para a organogênese. O presente trabalho objetivou a definição de um protocolo para a propagação in vitro de Hippeastrum hybridum Hort., para a produção massal de bulbilhos.

\section{MATERIAL E MÉTODOS}

Os experimentos foram desenvolvidos no Laboratório de Cultura de Tecidos do Centro de Horticultura (Setor de Floricultura e Plantas Ornamentais) do Instituto Agronômico de Campinas.
Utilizaram-se bulbos comerciais (aproximadamente $24 \mathrm{~cm}$ de perímetro) de amarílis (Hippeastrum hybridum) 'Apple Blossom'.

Inicialmente, os bulbos foram lavados com o auxílio de uma escova de cerdas finas, em água corrente e detergente comum, eliminando-se toda a terra, as partes escuras, todas as raízes e as escamas mais externas. Após esse procedimento, foram enxaguados com água destilada e, para a desinfecção, mergulhados em álcool $70 \%$ durante 30 segundos, retirados e imersos em solução de hipoclorito de cálcio a $3 \%$ mais 5 gotas de Tween 20 , por 10 minutos. Em seguida foram lavados, por três vezes sucessivas, com água destilada esterilizada.

Testes preliminares indicaram que o explante mais adequado para a micropropagação in vitro de amarílis é uma secção da base das escamas unidas à placa basal, conforme já haviam observado DE BRUYN et al. (1992).

Como explante, empregaram-se secções do bulbo com 5 × 5 x $3 \mathrm{~mm}$ de tamanho.

Realizaram-se dois experimentos. No experimento 1, o meio de cultura básico empregado foi o de MS e, a partir daí, estabeleceram-se diferentes concentrações de AIA $\left(0,0 ; 2,5\right.$ e 5,0 mg. $\left.\mathrm{L}^{-1}\right)$ e 6 -BA $\left(0,5 ; 10,0\right.$ e 20,0 mg. $\left.\mathrm{L}^{-1}\right)$, combinadas fatorialmente. $\mathrm{O} \mathrm{pH}$ foi ajustado para 6,0 , em todos os meios, solidificados com 6,2 g.L. $\mathrm{L}^{-1}$ de ágar e, em seguida, esterilizados em autoclave.

Adotou-se o delineamento em blocos ao acaso, com cinco repetições, contendo cinco frascos por parcela e um explante em cada frasco. Os ensaios permaneceram em câmara de cultivo, com fotoperíodo de 16 horas de luz, a uma temperatura de 25 $\pm 2^{\circ} \mathrm{C}$ e luminosidade de 1.500 Lux.

Realizaram-se as avaliações semanalmente, observando-se o número de bulbilhos formados e o comprimento da raiz mais longa em centímetros.

No Experimento 2, o meio de cultura básico empregado também foi o de MS, com 6-BA (10,0 $\left.\mathrm{mg} . \mathrm{L}^{-1}\right)$ e diferentes concentrações de AIA, AIB e ANA (2,5 e 5,0 mg. $\left.\mathrm{L}^{-1}\right)$, combinados fatorialmente.

$\mathrm{O}$ pH dos meios, a quantidade de ágar, esterilização do meio e demais condições de cultivo, bem como o delineamento, foram idênticos ao Tratamento 1 .

As avaliações foram realizadas semanalmente, sendo observado o número de bulbilhos e de raízes formados. 


\section{RESULTADOS E DISCUSSÃO}

\section{Experimento 1}

Logo após a inoculação, descartaram-se os frascos contendo os explantes que apresentaram contaminação por fungos e bactérias. O início do desenvolvimento dos explantes foi observado após 30 dias da inoculação.

\section{Número de bulbilhos}

$\mathrm{Na}$ Tabela 1, verifica-se que os tratamentos com 6-BA apresentaram um efeito quadrático, onde a formação de bulbilhos por explante variou de 0,88 a 1,60 , em média, sendo o ponto mais baixo da curva situado a $5 \mathrm{mg} . \mathrm{L}^{-1}$ de 6 -BA.

Tabela 1. Média por tratamento do número de bulbilhos formados por explante em diferentes combinações de AIA e 6-BA, na micropropagação de Hippeastrum 'Apple Blossom'

\begin{tabular}{|c|c|c|c|c|c|c|}
\hline \multirow{2}{*}{$\begin{array}{c}\text { 6-BA } \\
\left(\mathrm{mg} \cdot \mathrm{L}^{-1}\right)\end{array}$} & \multicolumn{3}{|c|}{ AIA (mg.L $\left.L^{-1}\right)$} & \multirow[b]{2}{*}{ F. $\operatorname{lin}}$. & \multirow[b]{2}{*}{ F.q. } & \multirow[b]{2}{*}{$\mathrm{R} 2$} \\
\hline & 0,0 & 2,5 & 5,0 & & & \\
\hline $0,0 \ldots$ & 1,12 & 1,00 & 1,04 & Ns & Ns & - \\
\hline $5,0 \ldots$ & 0,88 & 0,88 & 0,88 & Ns & Ns & - \\
\hline $10,0 \ldots$. & 1,16 & 1,60 & 1,24 & Ns & Ns & - \\
\hline $20,0 \ldots$. & 1,32 & 0,92 & 1,00 & Ns & Ns & - \\
\hline F.lin. ... & $* *$ & $* *$ & $* *$ & & & \\
\hline F.q. ..... & $* *$ & $* *$ & $* *$ & & & \\
\hline R2 ...... & 0,80 & 0,80 & 0,80 & & & \\
\hline
\end{tabular}

F.lin. = teste $\mathrm{F}$ para regressão linear. F.q. = teste $\mathrm{F}$ para regressão quadrática. Ns $=$ não significativo. ${ }^{*} *$ significativo ao nível de $1 \%$

Nos tratamentos cujas concentrações de 6-BA foram mais elevadas (10 a $20 \mathrm{mg} \cdot \mathrm{L}^{-1}$ ), verificaram-se os maiores números absolutos de bulbilhos formados: em alguns frascos foram formados até 4 ou 5 bulbilhos por explante.

A interação entre auxina e citocinina, a princípio, não exerceu estímulo sobre a bulbificação.

Contrariando os resultados de HUSSEY (1975), BOSE \& JANA (1977) e CASTRO \& MATTHES (1987), as auxinas não influenciaram na bulbificação dessa espécie. Ficou comprovado que a presença de 6-BA estimula a formação de bulbilhos, enquanto o AIA não exerceu nenhuma influência. $\mathrm{Na}$ rotina de laboratório, a utilização de 2,5-5,0 mg.L-1 de AIA e $10,0 \mathrm{mg} . \mathrm{L}^{-1}$ de 6 -BA foi a que promoveu melhores resultados.

Na Figura 1, observa-se a curva da formação do número de bulbilhos em relação à concentração de 6-BA e AIA. O pico da curva para o maior número de bulbilhos formados situa-se no meio com $5 \mathrm{mg} . \mathrm{L}^{-1}$ de 6-BA e 2,5 mg. $\mathrm{L}^{-1}$ de AIA. Observa-se também a curva de comprimento de raiz em relação à concentração de 6-BA e AIA, onde nota-se o efeito negativo do 6-BA.

\section{Comprimento de raiz}

Nos tratamentos sem a citocinina 6-BA, notou-se melhor crescimento das raízes nos explantes e com maior intensidade nas maiores concentrações de AIA (Tabela 2).

Tabela 2. Média por tratamento referente ao comprimento de raízes obtidas em diferentes concentrações entre combinações de AIA e 6-BA, na micropropagação de Hippeastrum 'Apple Blossom'

\begin{tabular}{|c|c|c|c|c|c|c|}
\hline \multirow{2}{*}{$\begin{array}{c}\text { 6-BA } \\
\left(\mathrm{mg} \cdot \mathrm{L}^{-1}\right)\end{array}$} & \multicolumn{3}{|c|}{$\operatorname{AIA}\left(m g . L^{-1}\right)$} & \multirow[b]{2}{*}{ F. lin. } & \multirow[b]{2}{*}{ F.q. } & \multirow[b]{2}{*}{$\mathrm{R} 2$} \\
\hline & 0,0 & 2,5 & 5,0 & & & \\
\hline $0,0 \ldots$ & 2,16 & 2,46 & 2,76 & Ns & Ns & - \\
\hline $5,0 \ldots$ & 1,60 & 0,30 & 0,93 & Ns & Ns & - \\
\hline $10,0 \ldots$. & 0,00 & 0,00 & 0,00 & Ns & Ns & - \\
\hline $20,0 \ldots$. & 0,20 & 0,40 & 0,00 & Ns & Ns & - \\
\hline F.lin. ... & $* *$ & $* *$ & $* *$ & & & \\
\hline F.q. ..... & $* *$ & $* *$ & $* *$ & & & \\
\hline R2 ..... 0 & 980,90 & 0,98 & & & & \\
\hline
\end{tabular}

F.lin. = teste $\mathrm{F}$ para regressão linear; F.q. = teste $\mathrm{F}$ para regressão quadrática; Ns = não significativo; $* *=$ significativo ao nível de $1 \%$.

A média de comprimento de raiz foi menor nos tratamentos com 6-BA, observação confirmada estatisticamente.

Pelos dados obtidos, o AIA não exerceu nenhuma influência sobre a formação de bulbilhos. Também, não houve interação entre as doses de AIA e 6-BA sobre o comprimento das raízes. 


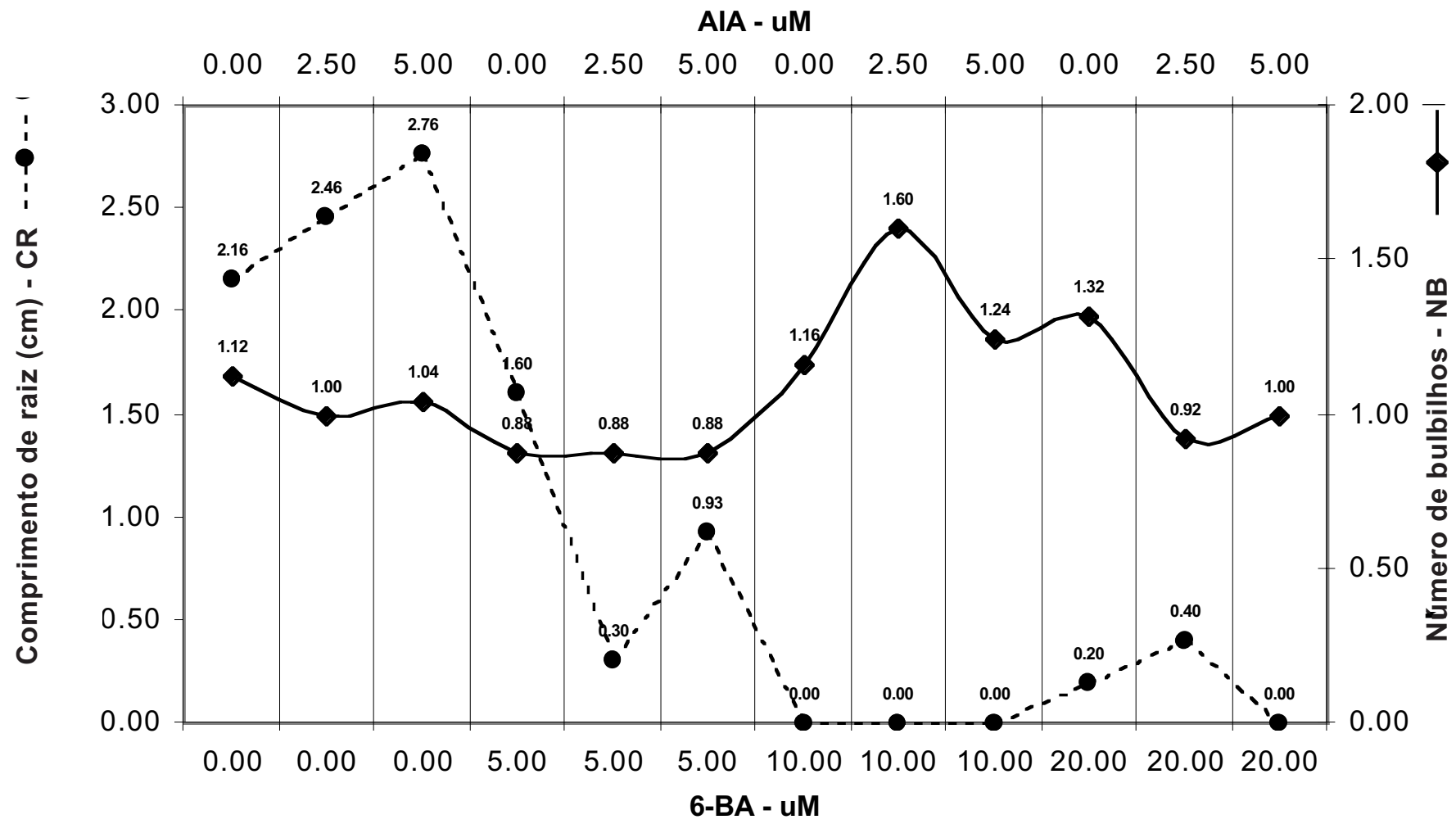

Figura 1. Médias dos números de bulbilhos e comprimentos das raízes de H. hybridum cultivado in vitro em diferentes combinações de AIA e 6-BA

\section{Experimento 2}

Verificou-se que, nas primeiras semanas, alguns frascos foram contaminados por bactérias e fungos, sendo descartados (Tabela 3). Os primeiros resultados dos tratamentos começaram a ser observados depois de 30 dias do início da cultura in vitro.

Tabela 3. Número de explantes inoculados e descartados, número total de explantes e média de bulbilhos formados/explante e número de raízes formadas/explante, obtidos na micropropagação de Hippeastrum 'Apple Blossom', em diferentes concentrações e tipos de auxinas

\begin{tabular}{|c|c|c|c|c|c|}
\hline Tratamento & $\begin{array}{l}\text { Explantes } \\
\text { inoculados }\end{array}$ & $\begin{array}{l}\text { Explantes des- } \\
\text { cartados por } \\
\text { contaminação }\end{array}$ & $\begin{array}{l}\text { Total de } \\
\text { bulbilhos } \\
\text { formados }\end{array}$ & $\begin{array}{l}\text { Média de } \\
\text { bulbilhos/ } \\
\text { explante }\end{array}$ & $\begin{array}{c}\text { Raízes } \\
\text { formadas/ } \\
\text { explante }\end{array}$ \\
\hline $\mathrm{mg} \cdot \mathrm{L}^{-1}$ & & & N. ${ }^{o}$ & & \\
\hline AIA $2,5 \ldots \ldots .$. & 25 & 07 & 29 & 1,6 & 19 \\
\hline AIB $2,5 \ldots \ldots .$. & 25 & 04 & 30 & 1,4 & 46 \\
\hline ANA $2,5 \ldots \ldots$. & 25 & 08 & 32 & 1,9 & 78 \\
\hline AIA $5,0 \ldots \ldots .$. & 25 & 03 & 46 & 2,1 & 08 \\
\hline AIB $5,0 \ldots \ldots$ & 25 & 07 & 29 & 1,6 & 32 \\
\hline ANA $5,0 \ldots \ldots$. & 25 & 08 & 19 & 1,1 & 90 \\
\hline
\end{tabular}


Os resultados não confirmaram as observações de CASTRO \& MATTHES (1987), quanto à influência da quantidade de auxina sobre o número de raízes formadas, porém mostraram um efeito positivo quanto ao tipo de auxina. Das auxinas testadas (ANA, AIA e AIB), o ANA, nas concentrações de 2,5 a 5,0 mg. $\mathrm{L}^{-1}$, combinado com $10 \mathrm{mg} . \mathrm{L}^{-1}$ de 6-BA, induziram a formação de um número extremamente elevado de raízes (alguns explantes apresentaram acima de 10 raízes), o que não é desejável nesse estádio inicial, quando o objetivo é a obtenção de maior número de bulbilhos. A menor formação de raízes foi observada no tratamento com AIA, na concentração de $5 \mathrm{mg} \cdot \mathrm{L}^{-1}$.

Nenhuma das auxinas testadas induziu à formação de calo nesses tipos de explantes.

Os meios mais favoráveis à micropropagação são aqueles que apresentam baixa indução de raiz e alta formação de bulbilhos. Dessa maneira, segundo este objetivo, o resultado mais favorável foi obtido nos tratamentos de 2,5 e 5,0 mg. $\mathrm{L}^{-1}$ de AIA e 10,0 mg.L ${ }^{-1}$ de 6-BA.

\section{CONCLUSÕES}

1. A presença de AIA, em qualquer concentração testada, não exerceu influência sobre os explantes;

2. A combinação de auxina com $10 \mathrm{mg} \cdot \mathrm{L}^{-1} \mathrm{de}$ 6-BA promoveu uma bulbificação mais intensa;

3. A presença de 6-BA inibiu o crescimento das raízes;

4. A alteração do tipo de auxina, estatisticamente, não promoveu alguma alteração na bulbificação;

5. AIA a 2,5 e 5,0 mg. $\mathrm{L}^{-1}$ combinado com 10 mg.L $\mathrm{L}^{-1}$ de 6-BA, promoveu a bulbificação múltipla com pouca formação de raízes.

\section{LITERATURA CITADA}

BAPAT, V.A. \& NARAYANASWANY. Growth and organogenesis in explanted tissues of Amaryllis in culture. Bulletin of the Torrey Botanical Club, New York, v.103, n.2, p. 53-56, 1976.
BELL, W.D. Culture of immature Amaryllis embryos. Plant Life, Pasadena, v.28, p.72-76, 1972.

BOSE, T.K. \& JANA, B.K. Regeneration of plantlets in Hyppeastrum in vitro. Indian Journal of Horticulture, Bangalore, v.34, n. 4, p.446-447, 1977.

CASTRO, C.E.F. \& MATTHES, L.A.F. Propagação vegetativa in vitro de Hippeastrum spp. I. Fontes de explantes e esterilização eficientes. In: CONGRESSO BRASILEIRO DE FLORICULTURA E PLANTAS ORNAMENTAIS, 6., Campinas, 1987. Anais... Campinas: SBFPO, 1987. p.128-139.

DE BRUYN, M.M.; FERREIRA, D.I.; SLABBERT, M.M. \& PRETORIOUS, J. In vitro propagation of Amaryllis belladonna. Plant Cell Tissue and Organ Culture, Dordrecht, v.31, n.3, p.179-184, 1992.

HUSSEY, G. Totipotency in tissue explant and callus of some members of the Liliaceae, Iridaceae and Amaryllidaceae. Journal of Experimental Botany, Oxford, v.26, n.91, p.253-262, 1975.

MII, M.; MORI, T. \& IWASE, N. Organ formation from the excised bulb scales of Hippeastrum hybridum in vitro. Journal of Horticultural Science, London, v.49, n. 3, p.241-244, 1974.

MURASHIGE, T. \& SKOOG, F. A revised medium for rapid growth and biossays with tobacco tissue cultures. Physiology Plantarum, Copenhagen, v.15, p 473-497, 1962.

O'ROURKE, E.N.; FOUNTAIN, W.M. \& SHARGHI, S. Propagation of Hippeastrum from floral tissues by in vitro culture. Herbertia, Pasadena, v.47, n.1. p.51-52, 1991.

TOMBOLATO, A.F.C. \& MATTHES, L.A.F. Collection of Hippeastrum spp., Alstroemeria spp. and other brazilian bulbous species. Acta Hort., Leiden, v.454, p. 91-98, 1998.

VIJVERBERG, A.J. Growing Amaryllis. London: Grower Books, 1981. 57 p. (Grower Guide, 23).

WHITE, P.R. Nutritional requirements of isolated plant tissues and organs. Annu.Rev.Plant Physiol., v.2, p.231244, 1951 .

YANAGAWA, T. \& SAKANISHI, Y. Regeneration of bulblets on Hippeastrum bulb segments excised from various parts of a parent bulb. Journal of the Japanese Society for Horticultural Science, v.46, n 2, p.250-260, 1977. 